\title{
Online PSO-tuned phase shift angle controller for dual active bridge DC-DC converter
}

\author{
Suliana Ab-Ghani ${ }^{1} \cdot$ Hamdan Daniyal ${ }^{1}$. Nur Huda Ramlan ${ }^{1} \cdot$ Meng Chung Tiong $^{1}$
}

Received: 20 August 2019 / Accepted: 23 November 2019 / Published online: 12 December 2019

(c) Springer Nature Switzerland AG 2019

\begin{abstract}
The deep concern towards efficient and green energy has brought to the development of intermediate energy storage system. Electric vehicles (EVs), for example, is an application where the energy storage devices are vital. In EV, the bidirectional DC-DC converter is high in demand due to its nature $E V$ of having two or more separate $D C$ sources. A recent technology called the dual active bridge (DAB) converter has quickly become popular in DC-DC converter thanks to its inherent galvanic isolation via a high-frequency transformer. Furthermore, DAB topology allows for high-efficiency conversion and soft switching adaption. This paper presents the optimization of the phase shift angle controller of DAB using Particle Swarm Optimization (PSO). From the preliminary study, it was found out that the optimization performs well until there are abrupt changes in the system. The system is not able to respond to the reference voltage step change as the traditional one-time execution PSO have local optima entrapped in react to the changes. The paper proposes a reset function to allow PSO to identify that its current optimized value is not optimal anymore. This drives PSO to look for a new optimal value to improve DAB's overall dynamic performance. Simulation of the modified PSO is done on a $200 \mathrm{~kW}$ $D A B$ system with $20 \mathrm{kHz}$ switching frequency is developed in MATLAB/Simulink environment. Simulation has been carried out with the objective to minimize the steady-state error as well as to improve the dynamic performance of the DAB. The DAB performance with the proposed solution is evaluated in terms of steady-state error and transient response by testing the system under various reference voltage and step-change input voltage. The self-excited re-exploration PSO also have been presented as to respond to the reference voltage step change as the basic PSO have local optima entrapped in react to the changes. In order to validate the simulation results, a hardware-in-the-loop (HIL) experimental circuit is built in Typhoon HIL-402 to verify the dynamic response and the steady state performance of the system.
\end{abstract}

Keywords Dual active bridge · Particle swarm optimization · Online tuning · Steady-state error · Dynamic performance

\section{Introduction}

Recently, electric vehicles (EVs) application has become an emerging technology in industry [1, 2]. The high demand of EVs application have carried to the development of intermediate storage system that required bidirectional power flow $[3,4]$. Hence, the dual active bridge (DAB) DC-DC converter are most chosen as power conversion platform due to high efficiency, zero voltage switching, galvanic isolation with high frequency transformer and high density [5-7].

Basically, the phase shift angle between primary and secondary bridge will determine the magnitude and direction of the power in DAB converter. Therefore, many modulation techniques have been applied in DAB system to control the power transmission such as single phase shift (SPS), extended phase shift (EPS), dual phase shift (DPS) and triple phase shift (TPS) [8]. The difference among the

$\triangle$ Hamdan Daniyal, hamdan@ump.edu.my| ${ }^{1}$ Faculty of Electrical and Electronics Engineering, Universiti Malaysia Pahang, 26600 Pekan, Pahang, Malaysia. 
aforementioned methods is the dimension control of the angle, which SPS is one dimension control as just control one angle between primary and secondary part. On the other hand, the two dimension control of EPS required one additional inner phase shift in primary or secondary bridge compared to the single dimension control in SPS. Whereas in DPS and TPS, both modulation have inner phase shift at primary and secondary bridges, which same degree for both inner phase shift in DPS is required and different degree should be applied in TPS modulation technique. In this paper, since the limited range of EV voltage is considered, the simplest and reliable of SPS modulation techniques is chosen as this technique can guarantee better efficiency and extend the soft switching region in $D A B$ converter $[3,6,8]$.

As to produce the optimal phase shift angle, many optimization technique have been proposed such as Lagrange multiplier method, mathematical programming methods, genetic algorithm (GA) and Ant Colony Optimization (ACO) $[6,9,10]$. Due to high computational burden and complicated techniques, an offline tuning method by using particle swarm optimization (PSO) is proposed in [6] where the swarm intelligence offers the advantages of reducing the computational load, easy to implement and high convergence speed. However, since the lookup table is required to implement the offline methods, it is not so practical to certain circumstances especially with the presence of disturbance in DAB system. Thus, the online tuning method using PSO algorithm is proposed in this paper to overwhelm the demerits of the offline tuning and offers a promising high robustness system.

\section{Operating principle converter}

The dual active bridge converter is a kind of DC-DC converter that have bidirectional power flow, galvanic isolation with high frequency transformer, high efficiency and high density features $[8,11,12]$. The DAB is a converter based on two active bridges interconnected through a high frequency transformer as depicted in Fig. 1. It comprise of four IGBT switches at each bridges, where the diagonal switches have same signal and the rest are complement to it. In forward direction, which power is transferring from the primary side to the secondary part, the pulse of S1 and S4 (primary bridge) will lead the pulse of S5 and S8 (secondary bridge) with certain degree of phase shift angle, $\phi$. In contrast, the secondary pulse will lead the primary pulse in backward direction where the primary bridge demands some power from the secondary part.

In $D A B$, each bridges produced symmetrical square pulses by giving $50 \%$ of duty ratio to all switches. Leakage inductance $L_{k}$ is use to transfer energy from primary to secondary bridges and vice versa. Equation (1) presents the formulae to calculate the $L_{k}$. The ratio of high frequency transformer and voltage conversion ratio of DAB can be determine by using Eqs. (2) and (3) respectively. As the SPS modulation is applied, the voltage conversion ratio, $k$ must close to one in ensuring soft switching and high efficiency in DAB [6]. Thus, the operating voltage that was considered in this paper is $250-420 \mathrm{~V}$ with range of $k$ is $0.67-1.12$.

$$
\begin{aligned}
& L_{k}=\frac{V_{1} n V_{2} \phi_{12}}{2 \pi f_{s} P_{12}}\left(1-\frac{\left|\phi_{12}\right|}{\pi}\right), \quad \phi_{12}=\phi_{1}-\phi_{2} \\
& n=\frac{V_{1}}{V_{2}} \\
& k=n \frac{V_{o}}{V_{\text {in }}} .
\end{aligned}
$$

\section{Particle swarm optimization algorithm}

Particle swarm optimization is a swarm intelligence that was initiated by Kennedy and Ebehart [13]. The PSO imitate the behavior of birds flock where its intelligence are able to resolve any optimization problems with group communications [14]. The PSO are chosen in this research paper due to its simplicity and efficient approach [15]. Starting with the
Fig. 1 Dual active bridge circuit configuration

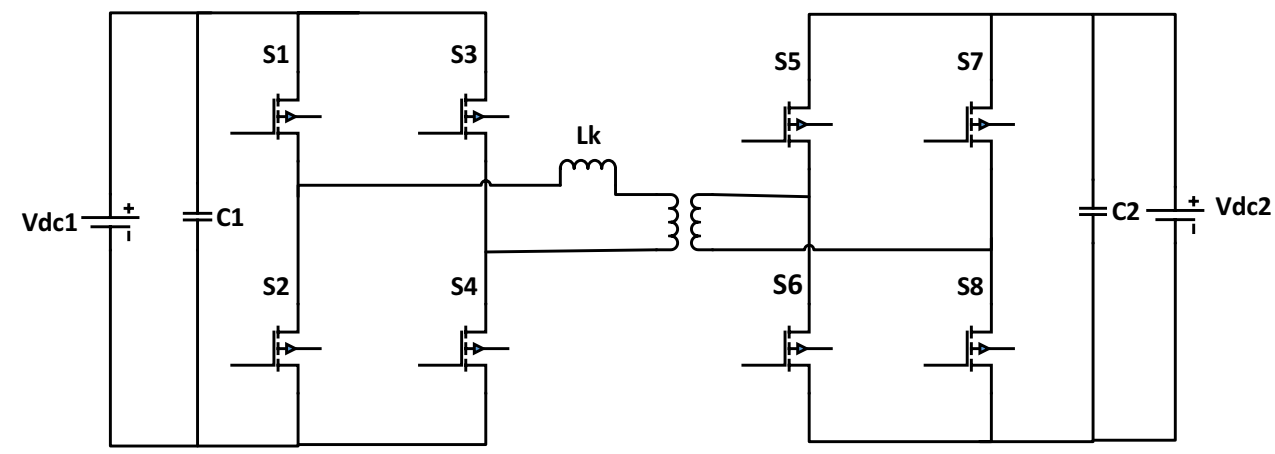


random initialization value of the phase shift angle (initial position), particles population doing the searching process. In PSO, each particles have potential solution that reflect to the optimization objective, where the minimum steady state error is the objective in this online tuning method.

Then, each particles will update its fitness and the best fitness will be keep as (best position of each particle $\left(P_{\text {best }}\right)$ in every iteration. The global best $\left(G_{\text {best }}\right)$ is the best fitness that was selected among the best particles. The position and velocity of the particles will be updated correspondingly using Eqs. (4) and (5) at the end of each iteration.

$v_{i}(k+1)=w v_{i}(k)+c_{1} r_{1} \cdot\left\{P_{\text {best }_{i}}-x_{i}(k)\right\}+c_{2} r_{2}\left\{G_{\text {best }}-x_{i}(k)\right\}$

$x_{i}(k+1)=x_{i} \cdot(k)+v_{i}(k+1)$

where, $w=$ inertia weight, $c_{1}$ and $c_{2}=$ acceleration coefficient, $r_{1}$ and $r_{2}=$ random number between $0-1, P_{\text {best }}=$ personal best position of particle $i, G_{\text {best }}=$ best position of the particles and $k$ representing the iteration number.

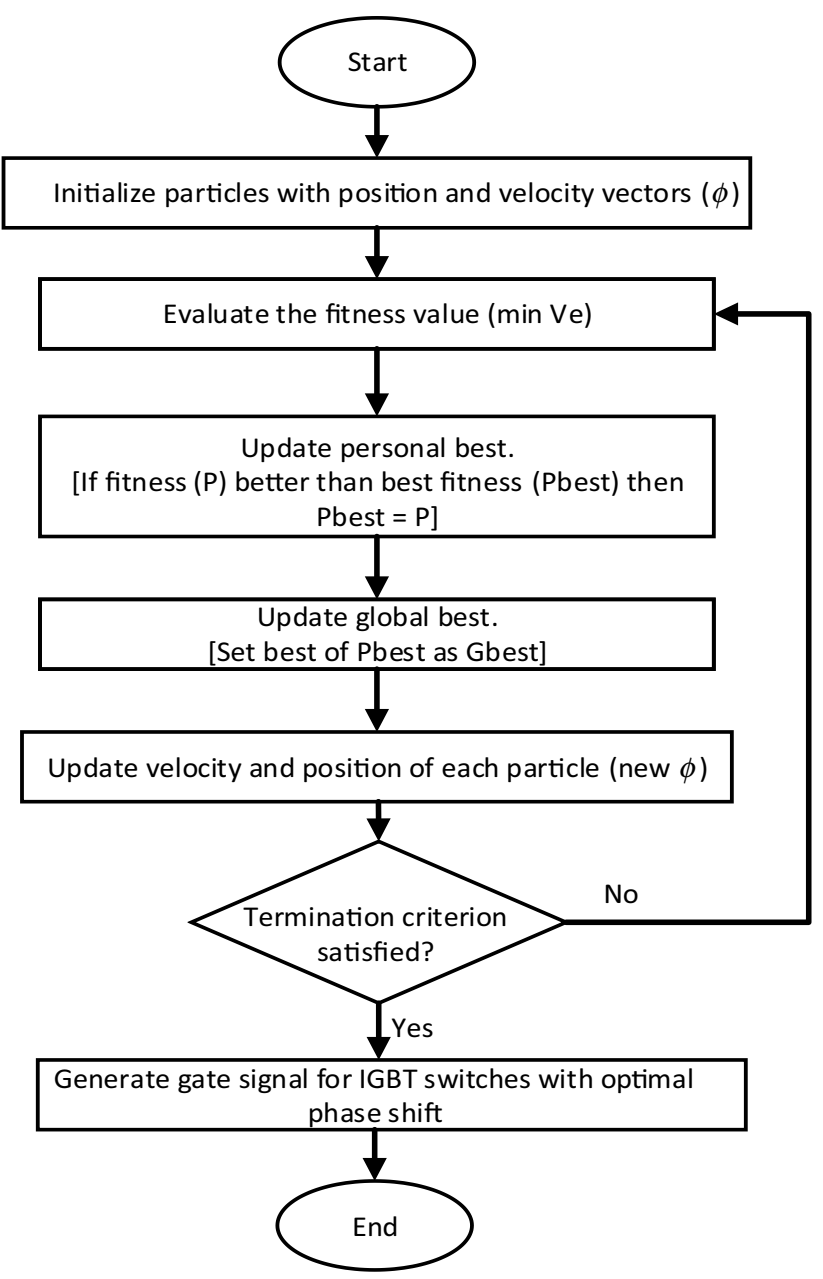

Fig. 2 Flowchart of the proposed algorithm
Lastly, the gate signal with optimal phase shift angle will be generated through IGBT switches to be used to run the DAB system accordingly. The flowchart and block diagram are represented in Figs. 2 and 3 respectively. By referring to Fig. 3, the closed loop system shows that the output voltage is being fed to the system and compared with reference voltage. The voltage error is sent into the PSO to determine the minimal steady state and optimized angle for the SPS as online tuning. The proposed method adjusts the $\phi$ according to the change and generate the performance as desired.

The simulation and experimental works of $20 \mathrm{kHz} D A B$ DC-DC converter was simulated and developed using the parameters as shown in Table 1. For real time verification, the DAB converter is built in Typhoon HIL-402 by using $\mathrm{TI}$ F28335 DSP control card as depicted in Fig. 4.

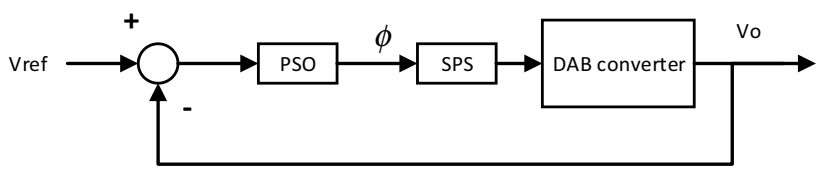

Fig. 3 Block diagram of the proposed algorithm

Table 1 Design parameters of DAB converter

\begin{tabular}{ll}
\hline Item & Parameter \\
\hline Transformer turns ratio, $n$ & 2 \\
Rated power, $P_{\max }$ & $200 \mathrm{~kW}$ \\
Switching frequency, $f_{s w}$ & $20 \mathrm{kHz}$ \\
Input voltage, $V_{\text {in }}$ & $750 \mathrm{~V}$ \\
Output voltage, $V_{o}$ & $500 \mathrm{~V}$ \\
Leakage inductance, $L_{k}$ & $24 \mu \mathrm{H}$ \\
\hline
\end{tabular}

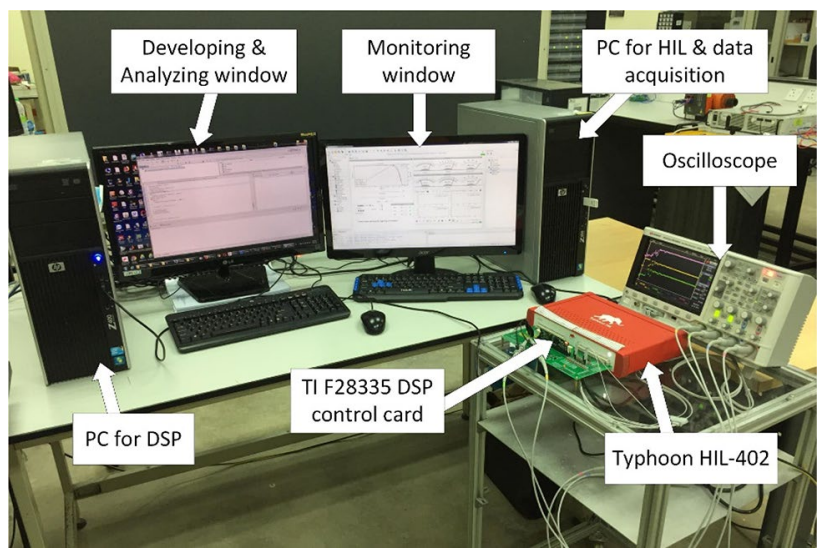

Fig. 4 Experimental setup 
Fig. 5 Square waveform and leakage inductance current

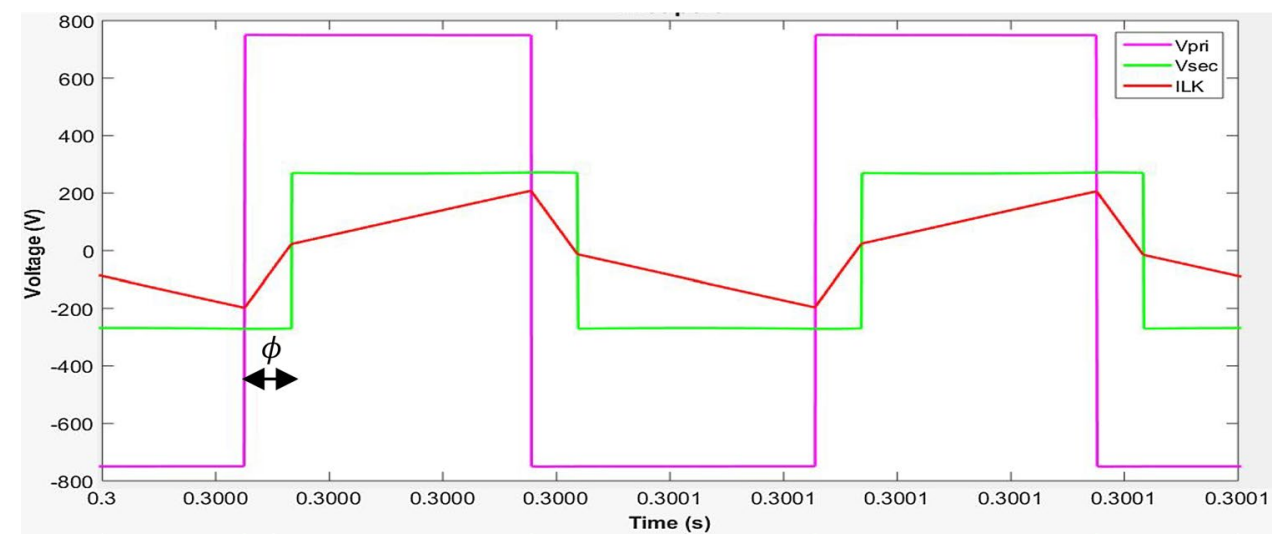

Fig. 6 Output voltage waveform under various voltage reference (simulation)
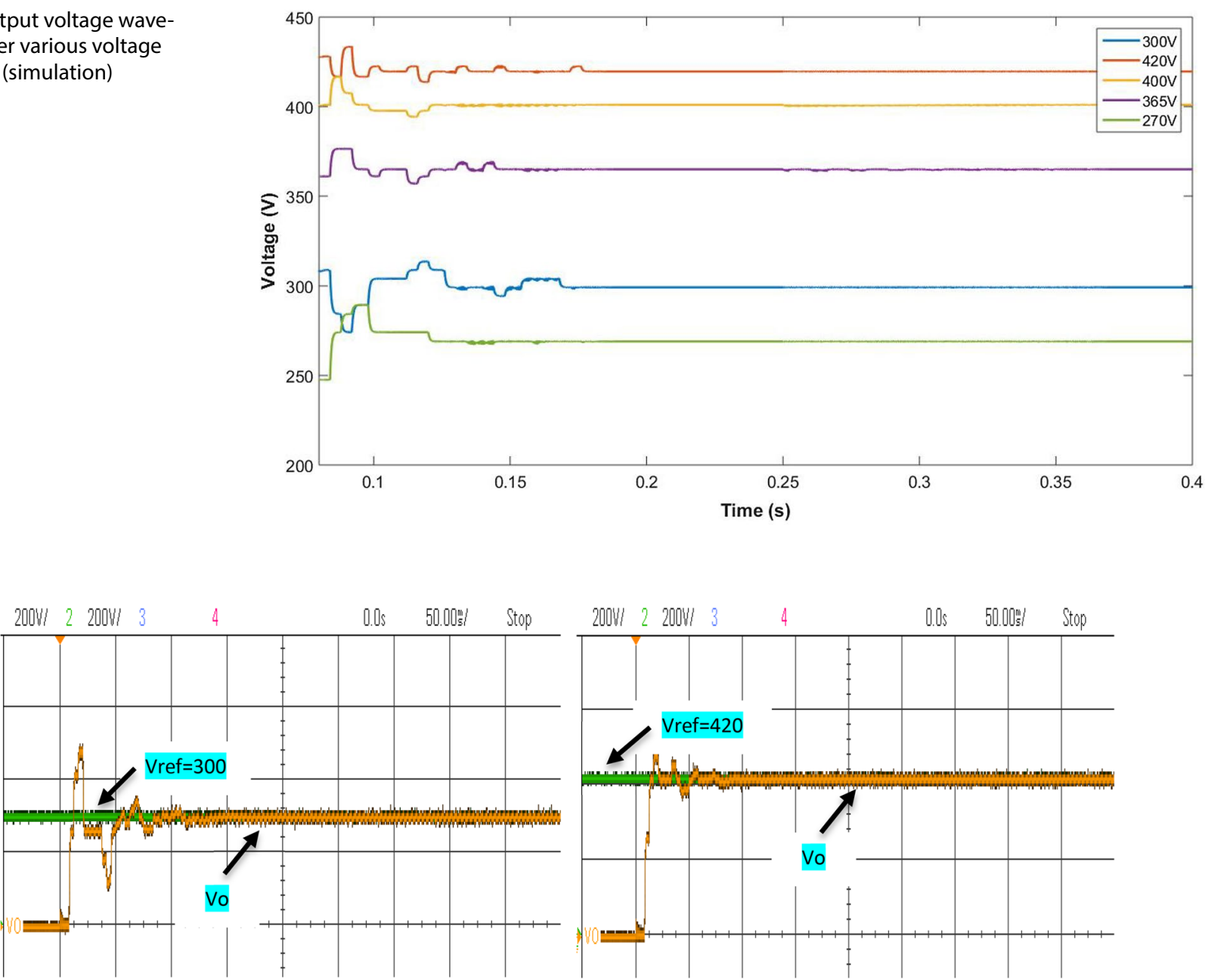

Fig. 7 Output voltage waveform under various voltage reference (experimental)

\section{Results and discussion}

In this paper, the DAB performance with PSO algorithm was tested under different reference voltage which are 270
V, $300 \mathrm{~V}, 365 \mathrm{~V}, 400 \mathrm{~V}$ and $420 \mathrm{~V}$. The step change for reference voltage and input voltage has also been established to evaluate the dynamic performance of the DAB system. In SPS modulation, only one angle, $\phi$ need to be controlled 
as shown in Fig. 5. The DAB performance in this research paper is analyzed in forward direction only. Hence, the primary pulse will lead the secondary pulse in all conditions with optimal phase shift angle.

Figures 6 and 7 demonstrate the basic PSO performance on output voltage waveforms under various voltage reference from simulation in Simulink and HIL validation results respectively. It depicts that all of the tested outputs can

Table 2 Results for difference reference voltages

\begin{tabular}{llllll}
\hline Vo $(\mathrm{V})$ & \multicolumn{2}{l}{ Steady state error (\%) } & & \multicolumn{2}{l}{ Settling time $(\mathrm{s})$} \\
\cline { 2 - 3 } \cline { 5 - 6 } \cline { 5 - 6 } & Simulation & Experimental & & Simulation & Experimental \\
\hline 270 & 0.62 & 1.81 & 0.1081 & 0.1570 \\
300 & 0.44 & 3.94 & 0.1331 & 0.1497 \\
365 & 0.48 & 1.89 & & 0.1047 & 0.1128 \\
400 & 0.70 & 1.65 & & 0.1043 & 0.1008 \\
420 & 1.11 & 2.45 & 0.1041 & 0.0970 \\
\hline
\end{tabular}

be regulated using the basic PSO methods and it shows that the PSO technique is valid to be used in DAB system. The steady state error produced are small, which are less than $4 \%$ in DAB as tabulated in Table 2 for both results. The good dynamic response have been proved by using PSO algorithm as the output voltages achieve the settling state around $0.15 \mathrm{~s}$.

Table 3 Dynamic response of DAB ( $V_{\text {in }}$ step change $)$

\begin{tabular}{llllll}
\hline $\mathrm{V}_{\text {ref }}(\mathrm{V})$ & \multicolumn{2}{l}{ Rise time $(\mathrm{s})$} & & \multicolumn{2}{l}{ Settling time $(\mathrm{s})$} \\
\cline { 2 - 3 } \cline { 5 - 6 } & Simulation & Experimental & & Simulation & Experimental \\
\hline 420 & 0.0009 & 0.0014 & & 0.3220 & 2.0718 \\
400 & 0.0010 & 0.0016 & & 0.3226 & 2.0716 \\
330 & 0.0010 & 0.0013 & & 0.3217 & 2.0715 \\
\hline
\end{tabular}

Fig. 8 Output voltage waveform with input voltage step change (simulation)

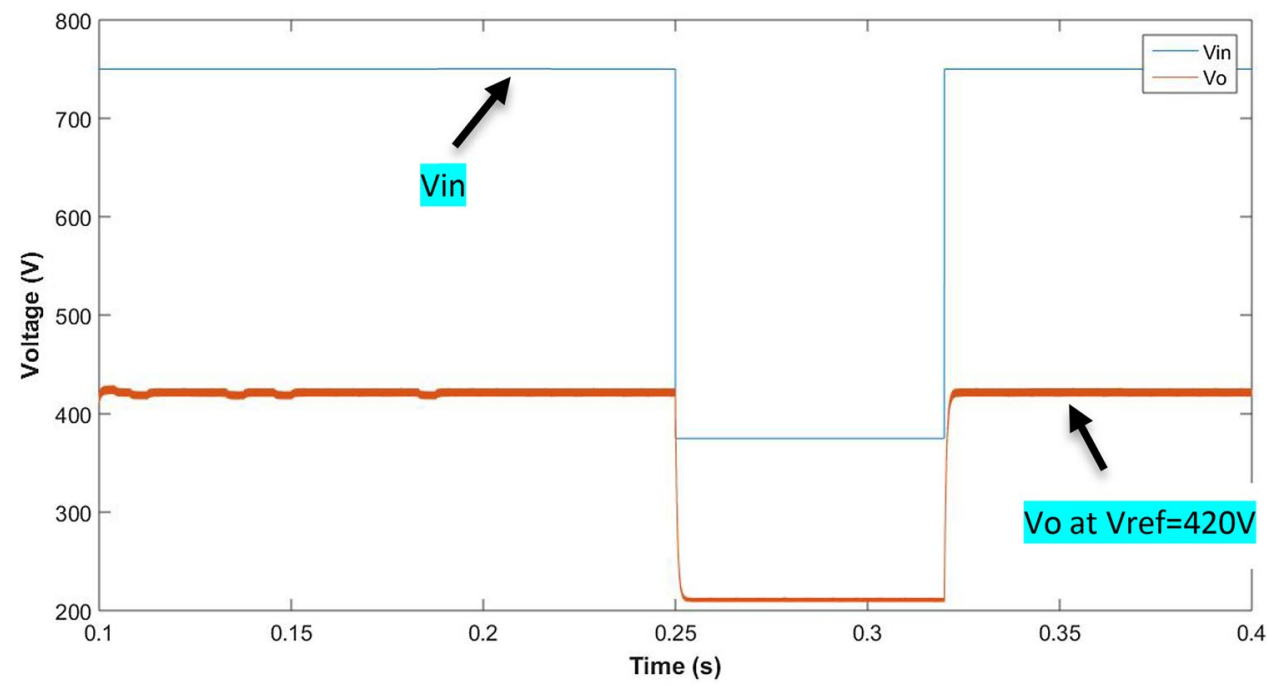

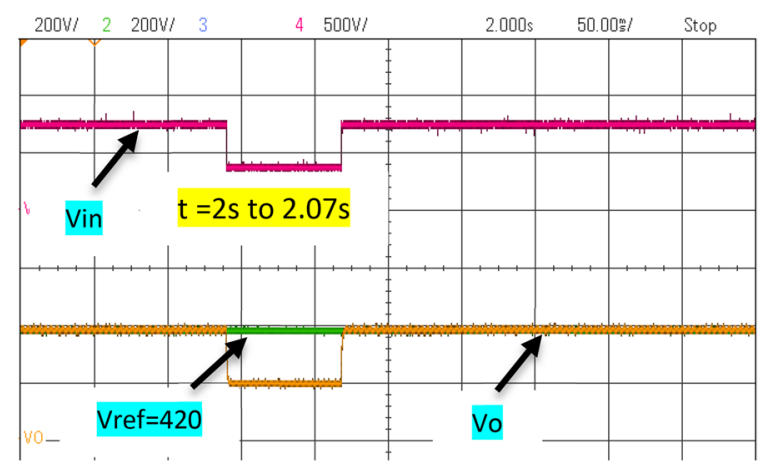

Fig. 9 Output voltage waveform with input voltage step change (experimental) 

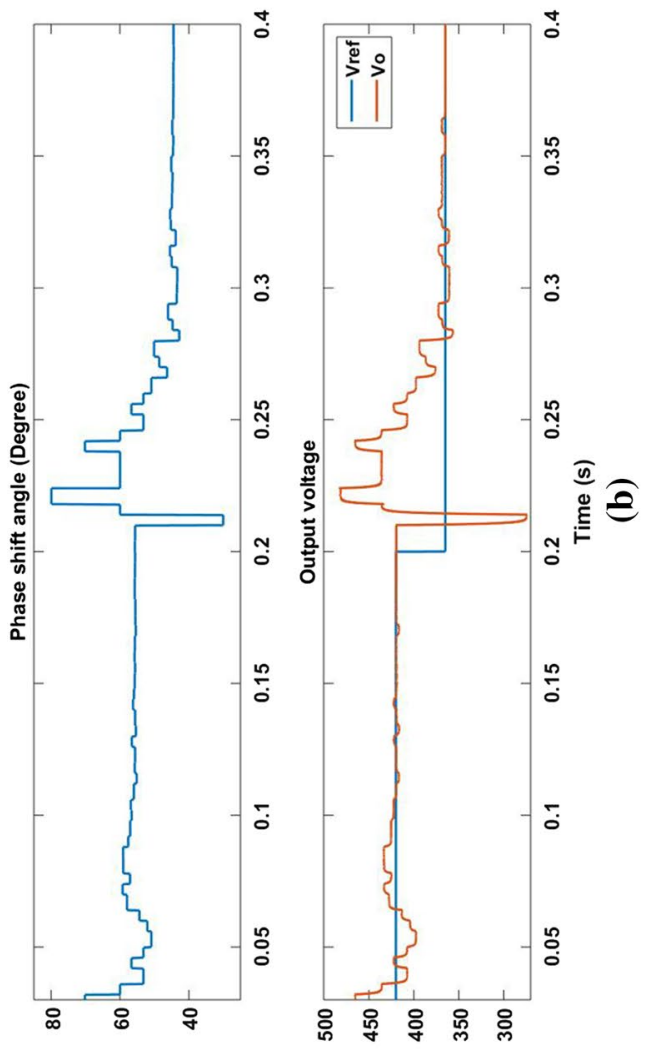

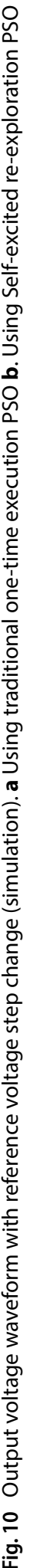

For input voltage step change condition, the input voltage steps is changed from 750 to $375 \mathrm{~V}$ for $0.07 \mathrm{~s}$. Figure 8 illustrates the output voltage waveform with the input voltage step change. It demonstrates that the controller is able to regulate the output voltage after disturbance occurred at $0.25-0.32 \mathrm{~s}$ in simulation work. While in experimental part, the step change is applied at $2-2.07 \mathrm{~s}$ as presented in Fig. 9. These results show that the proposed basic PSO controller guarantees fast dynamic response which allow the output voltage to response dynamically when input voltage is reduced in certain periods of time. Table 3 presented the DAB transient response in terms of rise time and settling time to verify the dynamic performance of the proposed controller during the step change of input voltage.

Figure 10a shows the output voltage waveform with reference voltage step change using the proposed traditional one-time execution PSO controller. It illustrates that the phase shift angle is unable to change due to the local optima problem in the PSO, which the output voltage does not follow the desired voltage after step change is applied at $0.2 \mathrm{~s}$. In order to solve this issue, the basic PSO is modified to enable the system to respond to the changes. Figures $10 \mathrm{~b}$ and 11 shows the simulation and experimental results of the output voltage waveform with reference voltage step change using the proposed self-excited reexploration PSO controller respectively. The phase shift angle is able to change according to the applied voltage changes at $0.2 \mathrm{~s}$ in simulation and $2 \mathrm{~s}$ during experimental and generate the desired output voltage. Table 4 presented the DAB dynamic response in terms of steady-state error percentage and settling time to verify the dynamic performance of the proposed controller during the step change of the reference voltage. The DAB dynamic performance is demonstrated where the output voltages respond and changed to the desired voltage in less than $0.15 \mathrm{~s}$ after the reference voltage changes are applied in both simulation and experimental results as can be seen in Table 4. 

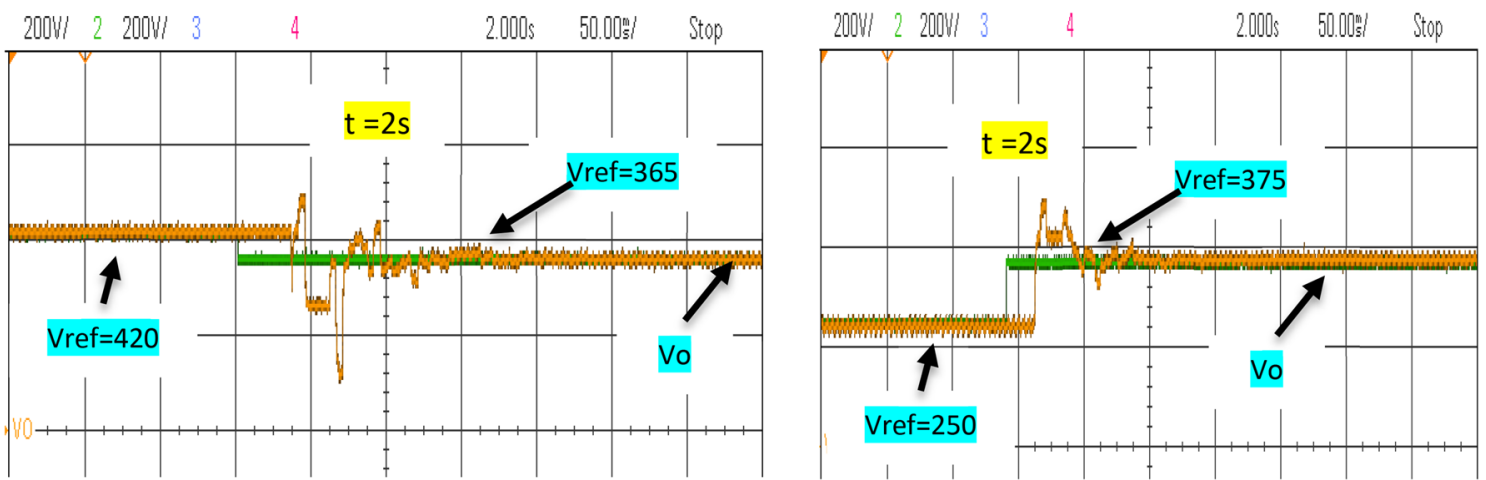

Fig. 11 Output voltage waveform with reference voltage step change using Self-excited re-exploration PSO (experimental)

Table 4 Dynamic response of DAB ( $\mathrm{V}_{\text {ref }}$ step change)

\begin{tabular}{|c|c|c|c|c|}
\hline \multirow[t]{2}{*}{ Step $V_{\text {ref }}(V)$} & \multicolumn{2}{|c|}{ Steady-state error (\%) } & \multicolumn{2}{|c|}{ Settling time (s) } \\
\hline & Simulation & Experimental & Simulation & Experimental \\
\hline $420-365$ & 0.48 & 2.07 & 0.3627 & 2.1261 \\
\hline $300-420$ & 0.96 & 2.82 & 0.3442 & 2.0970 \\
\hline $250-375$ & 0.80 & 3.30 & 0.3359 & 2.0900 \\
\hline
\end{tabular}

\section{Conclusion}

This paper has proposed the online tuning phase shift angle of DAB DC-DC converter using traditional onetime execution PSO algorithm and using Self-excited reexploration PSO algorithm. The optimal phase shift angle produced the output voltage with minimal steady state error and good dynamic response for various reference voltages, input voltage step changes and reference voltage step changes. The simulation and experimental results show that the proposed method can produce less than $5 \%$ steady state error and have good performance of transient response.

Acknowledgements This work is supported by Faculty of Electrical and Electronics Engineering, Universiti Malaysia Pahang, under research Grant RDU1703129.

\section{Compliance with ethical standards}

Conflict of interest The authors declare that they have no conflict of interest.

\section{References}

1. Dominguez-Navarro JA, Dufo-Lopez R, Yusta-Loyo JM, ArtalSevil JS, Bernal-Agustin JL (2019) Electrical power and energy systems design of an electric vehicle fast-charging station with integration of renewable energy and storage systems. Electr Power Energy Syst 105:46-58

2. Evangelou SA, Rehman-Shaikh MA (2017) Hybrid electric vehicle fuel minimization by DC-DC converter dual-phase-shift control. Control Eng Pract 64:44-60

3. Rodriguez A, Vazquez A, Lamar DG, Hernando MM, Sebastian J (2015) Different purpose design strategies and techniques to improve the performance of a Dual Active Bridge with phaseshift control. IEEE Trans Power Electron 30(2):790-803

4. Zhao B, Member S, Yu Q, Sun W (2012) Extended-phaseshift control of isolated bidirectional DC-DC converter for power distribution in microgrid. IEEE Trans Power Electron 27(11):4667-4680

5. Akagi $\mathrm{H}$, Yamagishi T, Tan NML, Miyazaki Y, Kinouchi SI, Koyama M (2015) Power-loss breakdown of a 750-V 100-kW 20-kHz bidirectional isolated DC-DC converter using SiC-MOSFET/SBD dual modules. IEEE Trans Ind Appl 51(1):420-428

6. Shi H, Wen H, Hu Y, Member S, Jiang L (2018) Reactive power minimization in bidirectional DC- DC converters using a unifiedphasor-based particle swarm optimization. IEEE Trans Power Electron 33(12):10990-11006

7. Shi Y, Li R, Xue Y, Li H (2015) Optimized operation of current-fed dual active bridge DC-DC converter for PV applications. IEEE Trans Ind Electron 62(11):6986-6995

8. Zhao B, Song Q, Liu W, Sun Y (2014) Overview of dual-activebridge isolated bidirectional DC-DC converter for high-frequency-link power-conversion system. IEEE Trans Power Electron 29(8):4091-4106

9. Zhang $H$, Tong $X$, Jin $Y(2017)$ Optimal triple phase shift controller design of isolated bidirectional DC-DC converter based on Ant Colony Algorithm and BP Neural Network. IN: IECON 2017-43rd annual conference on IEEE industrial electronics society, pp 8802-8807

10. Lei T, Wu C, Liu X (2018) Multi-objective optimization control for the aerospace dual-active bridge power converter. Energies 11:1168

11. Xiong F, Wu J, Liu Z, Hao L (2018) Current sensorless control for dual active bridge DC-DC converter with estimated loadcurrent feedforward. IEEE Trans Power Electron 33(4):3552-3566

12. Cho YW, Cha WJ, Kwon JM, Kwon BH (2016) High-efficiency bidirectional DAB inverter using a novel hybrid modulation for stand-alone power generating system with low input voltage. IEEE Trans Power Electron 31(6):4138-4147

13. Kennedy J, Eberhart R (1995) Particle swarm optimization. In: Proceedings of IEEE international conference on neural networks, vol 4, pp 1942-1948 
14. Eswaran T, Kumar VS (2017) Particle swarm optimization (PSO)based tuning technique for PI controller for management of a distributed static synchronous compensator (DSTATCOM) for improved dynamic response and power quality. Rev Mex Trastor Aliment 15(2):173-189

15. Liu Y, Huang S, Huang J, Liang W (2012) A particle swarm optimization-based maximum power point tracking algorithm for PV systems. IEEE Trans Energy Convers 27(4):1027-1035
Publisher's Note Springer Nature remains neutral with regard to jurisdictional claims in published maps and institutional affiliations. 